\title{
PENGENALAN TEKNOLOGI INTERNET BERBASIS SMARTPHONE UNTUK WISATA KULINER KHAS MELAYU BAGI IBU-IBU PENGUSAHA MAKANAN DI KECAMATAN MEDAN LABUHAN
}

\section{Introduction Of Smartphone-Based Internet Technology For Special Culinary Tours For Wood Food Business Mothers In Medan Labuhan District}

\author{
Ummul Khair' \\ Suriati $^{2}$ \\ Dharmawati $^{3}$ \\ *1,2,3 Universitas Harapan, \\ Medan, Sumatera Utara, \\ Indonesia \\ *email: ummul.kh@gmail.com
}

Kata Kunci:

Smartphone

Kuliner

Pengusaha Makanan

\section{Keywords:}

Smartphone

Culinary

Food Enterpreneur

\begin{abstract}
Abstrak
Pengabdian yang dilakukan ini adalah membantu ibu - ibu pengusaha makanan khas melayu yang boleh dikatakan kurang komersil diantar kuliner lainya, dikarenakan sewaktu peneliti melakukan survey ke Medan labuhan beberapa waktu lalu, banyak sekali ibu - ibu pengusaha makanan khas melayu mengeluhkan bahwa produknya susah dijual, tidak banyak peminatnya, sementara kalau hanya mengharapkan pembeli lokal, hamper semua masyarakat pandai memasak makanan dan kue khas melayu. $\mathrm{Hal}$ ini membuat penulis yang bergelut dibidang IT tergerak untuk membatu ibu - ibu tersebut mengemabngkan usahanya dengan memanfaatkan internet yang menggunakan smart phone untuk mengiklankan makanan yang mereka buat. Banyaknya kuliner atau masakan asing yang masuk ke Indonesia tidak menuntut kemungkinan kelestarian kuliner tradisional Indonesai semakin terkikis oleh zaman. Oleh sebab itu pelestarian kuliner tradisional harus dilakukan karena merupakan bagian dari kebudayan Indonesia. Oleh karena itu pemanfaatan teknologi sangatlah penting untuk menjaga kelestarian kuliner tradisional dan menyampaikannya kepada masyarakat khususnya generasi muda saat ini.
\end{abstract}

\begin{abstract}
The Community Engagement activity is done this time is to help the Malay traditional food entrepreneurs who can be said to be less commercial among other culinaries, because when the team Community Engagement conducts a survey to Medan Labuhan a few days ago, there were many Malay traditional food entrepreneurs complaining that their products were difficult to sell, not much demand. If you only expect local buyers, almost all people are good at cooking Malay food and cakes. This makes the team who is struggling in the field of IT to help these women to expand their business by utilizing the internet that uses smartphones to advertise the food they make. The number of culinary or foreign dishes that enter Indonesia does not require the possibility of preserving Indonesia's traditional culinary increasingly eroded by the times. Therefore preservation of traditional culinary must be done because it is part of Indonesian culture. Therefore, the use of technology is very important to preserve traditional culinary and convey it to the public, especially the young generation today.
\end{abstract}




\section{PENDAHULUAN}

Kecamatan Medan Labuhan adalah kecamatan yang ada di kota Medan, Provinsi Sumatera Utara. Kecamatan ini berbatasan langsung dengan Kecamatan Medan Marelan, Kabupaten Deli Serdang, dan Kecamatan Medan Belawan. Kecamatan ini merupakan daerah yang memiliki enam (6) kelurahan. Saat ini kecamatan Medan Labuhan sedang giat - giatnya berkembang melestarikan budaya melayu, baik dari sektor pendidikan, kesejahteraan masyarakat, ekonomi wisata maupun kuliner. Masyarakat yang mayoritas adalah suku melayu asli membuat suasana melayu sangat kental di kecamatan ini, mulai dari arsitektur bangunan, adat istiadat, bahasa, tutur sapa, busana bahkan makanan khas mudah dicari disini. Pada hari jadi Kota Medan ke-428 tahun 2018 yang lalu di Lapangan Benteng Medan, Selasa (2/7/2018). Kecamatan dan Kelurahan Terbaik Tingkat Kota Kecamatan Medan Labuhan ditetapkan sebagai juara pertama. Sebagai bentu apresiasi atas keberhasilan yang diraih tersebut, Wali Kota Medan Drs H T Dzulmi Eldin S MSi pun menyerahkan piala kepada Camat Medan Labuhan Arrahman Pane. Dengan keberhasilan ini membuat Medan Labuhan semakin terkenal diantara kecamatan lainya. Wali Kota berharap penilaian kecamatan terbaik dapat memotivasi para camat semakin meningkatkan kinerja dalam rangka memajukan wilayahnya masing-masing, terutama memberikan pelayanan terbaik kepada seluruh lapisan masyarakat.

Pengabdian yang dilakukan kali ini adalah membantu ibu - ibu pengusaha makanan khas melayu yang boleh dikatakan kurang komersil diantara kuliner lainya, dikarenakan sewaktu tim pengabdian melakukan survey ke Medan Labuhan beberapa waktu lalu, banyak sekali ibu - ibu pengusaha makanan khas melayu mengeluhkan bahwa produknya susah dijual, tidak banyak peminatnya, sementara kalau hanya mengharapkan pembeli lokal, hampir semua masyarakat pandai memasak makanan dan kue khas melayu. Hal ini membuat peneliti yang bergelut dibidang IT tergerak untuk membatu ibu - ibu tersebut mengembangkan usahanya dengan memanfaatkan internet yang menggunakan smartphone untuk mengiklankan makanan yang mereka buat.

Smartphone adalah kombinasi fungsi dari personal digital asistant (PDA) atau pocket personal computer (pocket PC) dengan telepon (Sawyer and Williams, 20II). Selain membuat panggilan telepon, penggunanya bisa memainkan game, chat dengan teman-teman, menggunakan sistem messenger, akses ke layanan web (seperti blog, homepage, jaringan sosial) dan pencarian berbagai informasi (Choi et al., 20I5). Kemajuan tekologi smartphone kian hari kian pesat, pada tataran fungsi teknologi telah membawa smartphone menjadi sebuah perangkat yang multi guna. Tidak hanya untuk komunikasi visual dan verbal saja, tetapi manfaat smartphone juga telah menjadi sebuah alat yang mendukung kinerja manusia dalam berbagai aktifitas

Banyaknya kuliner atau masakan asing yang masuk ke Indonesia tidak menuntut kemungkinan kelestarian kuliner tradisional Indonesai semakin terkikis oleh zaman. Oleh sebab itu pelestarian kuliner tradisional harus dilakukan karena merupakan bagian dari kebudayan Indonesia. Oleh karena itu pemanfaatan teknologi sangatlah penting untuk menjaga kelestarian kuliner tradisional dan menyampaikannya kepada masyarakat khususnya generasi muda saat ini.

\section{METODOLOGI}

Tim pengabdian masyarakat melakukan 3 (tiga) metode dalam mendongkrak kepopuleran dan penjualan makanan khas melayu produksi ibu - ibu UKM di Desa Pekan Labuhan. Hal yang dilakukan adalah mewajibkan seluruh peserta membawa semua produk dan deskripsi dari produknya. Dengan membawa produknya, ibu - ibu pengusaha kuliner akan 
langsung praktek bagaimana cara mengemas produknya hingga tampilanya menarik, metode tersebut adalah:

a) Langkah Pertama adalah mengajari ibu - ibu pengusaha kuliner menginstal aplikasi FB, WA dan IG di smartphone masing- masing.

b) Setelah aplikasi terpasang kami mengajarkan ibu- ibu tersebut menyusun dan mengemas kue- kue yang dibawa untuk di upload ke FB, WA dan IG

c) Langkah yang ke tiga adalah teknik pengambilan foto, mengedit dan mengupload foto makanan ke FB, WA dan IG

Tahapan pelaksanaan dibawah ini menggambarkan langkah- langkah yang dilakukan dalam melaksanakan kegiatan pengabdian masyarakat di kecamatan Medan Labuhan. Tahapan ini dilakukan agar target serta solusi yang ditawarkan dapat berhasil dilakukan. Adapun langkah- langkah yang dilakukan adalah sebagi berikut :

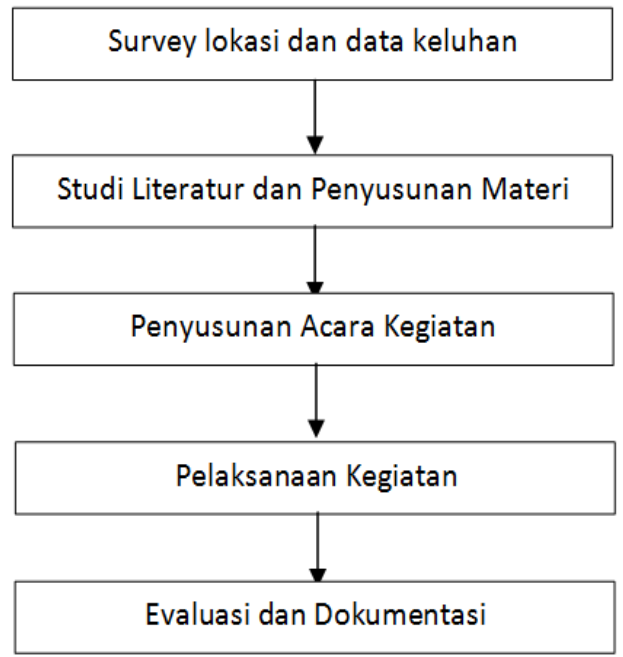

Gambar I Langkah - langkah kegiatan

Dari langkah - langkah diatas dapat dijabarkan sebagai berikut :

I) Survey lokasi dan data keluhan

Tahap ini dilakukan untuk melihat langsung kondisi lapangan dan mendata keluhan ibu - ibu tentang produknya yang kurang menjual, kami mencatat dan mendengarkan semua keluhan sehingga dapat dicarikan solusinya.
2) Studi Literaturatur dan Penyusunan Materi=

Pada tahap ini dilakukan untuk mempelajari studi yang lebih mendalam dalam bidang IT khusunya internet dan aplikasi samatphone serta hal - hal yang berkaitan dalam pengolahan data sehingga nantinya dapat digunakan untuk membatu menyusun materi workshop ke ibu - ibu pengusaha kuliner.

3) Penyusunan Acara Kegiatan

Tahapan ini untuk jadwal pelaksaan workshop, pengolahan makanan dan pembuatan label serta kemasan yang menarik.

4) Pelaksanaan Kegiatan

Kegiatan ini dirancang sebanyak 4 (empat) $x$ pertemuan dengan materi yang berbeda setiap pertemuan. Dengan jadwal kegiatan adalah bulan pertama melakukan survey, bulan ke dua mengadakan workshop penggunaan internet dan smartphone sebagai lahan bisnis, bulan ketiga melakukan olah makanan tradisional yang dihias modern dan cara pengemasan serta penyajian, dan bulan ke empat, pelatihan membuat kemasan dari makanan yang telah di olah.

5) Evaluasi dan Dokumentasi

Ini adalah tahapan teraakhir dari rangkaian kegiatan pengabdian ini. Tahap ini mengevaluasi kinerja selama 4 bulan apakah berhasil atau tidak, dan pada tahap ini juga dilakukan pembuatan jurnal yang akan dipublikasikan.

\section{HASIL DAN PEMBAHASAN}

Pelaksanaan yang telah dilakukan peneliti bersama tim, ada I5 peserta UKM Makananan khas melayu yang kami undang, kami hanya mengundang I5 UKM untuk memaksimalkan pelatihan yang kami berikan dapat diserap dan di aplikasikan. Peserta UKM yang kami undang adalah: 
Tabel I. Peserta dan Produk UKM

\begin{tabular}{|l|l|l|}
\hline No. & \multicolumn{1}{|c|}{ Naman Peserta } & \multicolumn{1}{c|}{ Produk UKM } \\
\hline 1. & Maharany & Kue Gorengan \\
\hline 2. & Junita Tridahniar Pasaribu & Mie Sop / Nuget \\
\hline 3. & Juli Sartika & Kripik Ubi Kayu \\
\hline 4. & Elva Trisnawati & Kue Basah \\
\hline 5. & Armaliah & Kue Basah \\
\hline 6. & Ramlah & Kue Kering \\
\hline 7. & Farida Hanum Siregar & Kue Bolu \\
\hline 8. & Sri Wahyuni & Mie Sop / Nuget \\
\hline 9. & Maulida & Stick Keju / Mpek-Mpek \\
\hline 10. & Hermayani Nasution & Nasi Goreng / Jus \\
\hline 11. & Nurcahaya & Manisan Buah \\
\hline 12. & Yenni Marlina & Kue / Gorengan \\
\hline 13. & Dilla Suplya & Kue Kering \\
\hline 14. & Ulfa Rizqil & Kebab dan Burger \\
\hline 15. & Susilawati & Gorengan / Bakso \\
\hline
\end{tabular}

Hasil pelatihan yang kami lakukan, antusias peserta sangat bersemangat belajar menginstal aplikasi cukup seru karena pesertanya ibu-ibu rumah tangga yang memang minim pengetahuan teknologi, namun semangat mereka membuat kami tak kenal lelah mengulang materi dan melayani satu persatu peserta.

Seperti yang disampaikan diatas, bahwa peserta kami wajibkan membawa kue-kue yang mereka buat sendiri untuk dapat dipraktekkan cara mengemas dan menjualnya dengan on-line. Sebagai contoh ini adalah kue yang dibawa oleh salah seorang pengusaha makanan. Ini merupakan kemasan asli yang belum di ubah, hanya dengan kemasan plastik mika biasa dan dijual Rp. 2000 / pak, I pak isinya 4 buag kue, sangat murah bukan?

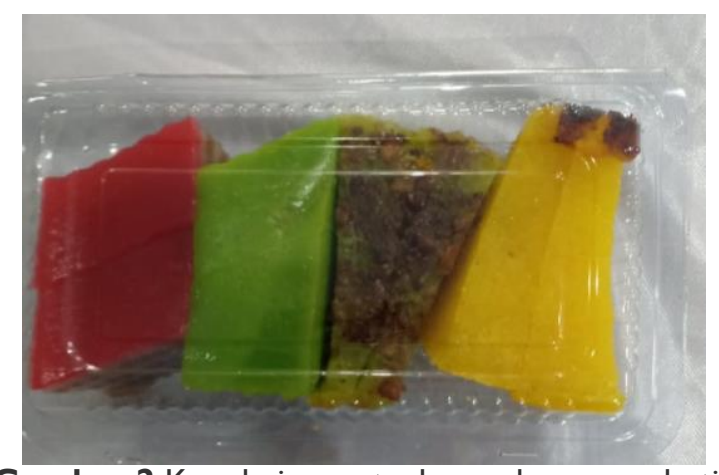

Gambar 2 Kue dari peserta dengan kemasan plastik mika

Setelah itu tim pengabdian mengajarkan peserta bagaimana cara mengedit di FB, IG dan WA seperti berikut :

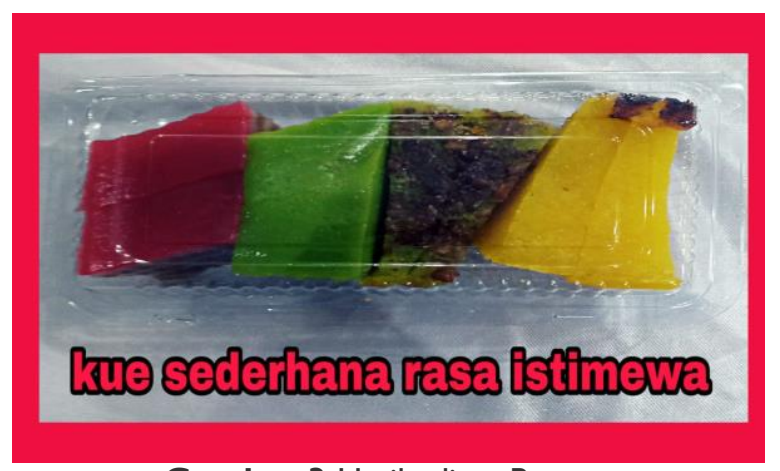

Gambar 3 Hasil editan Peserta

Selanjutnya kami juga mengajarkan cara mengemas dan menyusun makanan sehingga tampil menarik untuk dijual online.

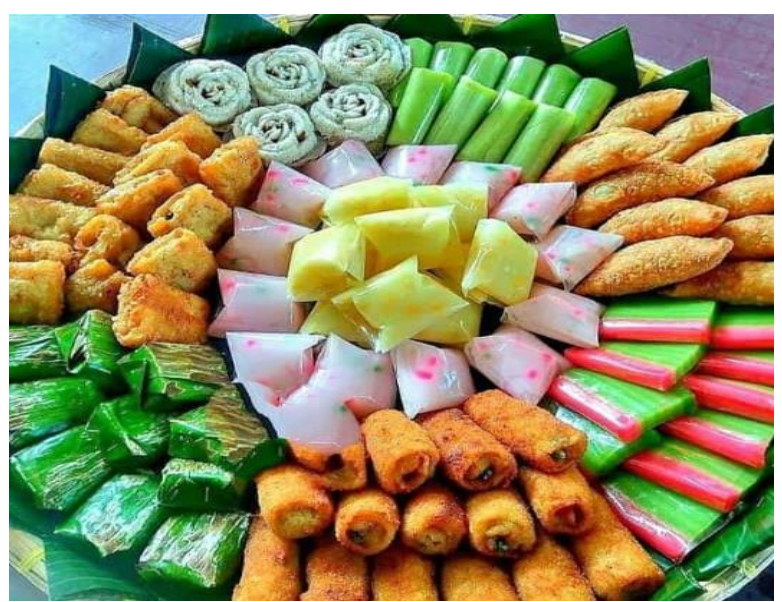

Gambar 4 Kue yang sudah disusun dan dikemas

Ini merupakan hasil susunan dan pengemasan kue-kue yang dibuat dengan tampilan menarik sehingga layak untuk dijual.

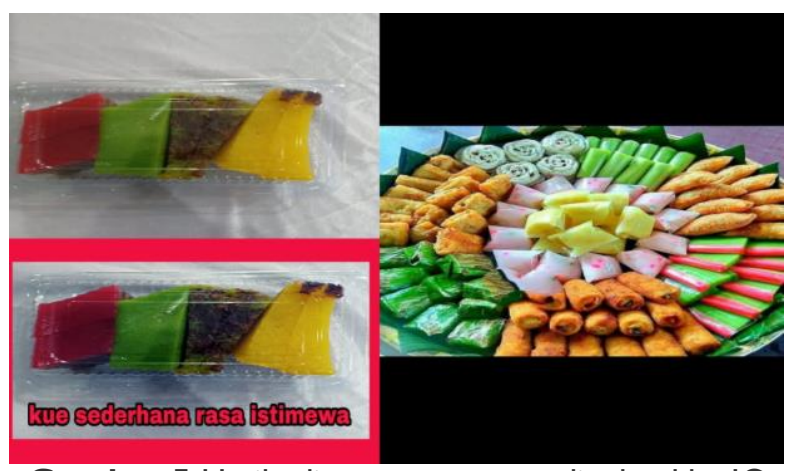

Gambar 5 Hasil editan peserta yang diupload ke IG dan Facebook

\section{KESIMPULAN}

Kegiatan pengabdian pada masyarakat ini dilakukan di kantor camat Kecamatan Medan Labuhan yang diikuti oleh ibu-ibu pengusaha makanan kue 
tradisional di lingkungan kecamatan Medan Labuhan. Dalam kegiatan ini peserta telah lebih dahulu membawa produk kue-kue yang mereka buat dan diajarkan untuk mengemas, mengedit dan mengupload produk kue yang telah tampil lebih menarik ke sosial media seperti ig. Peserta kegiatan sangat antusias mengikuti kegiatan pengabdian ini yang dibuktikan dengan hampir $90 \%$ peserta dapat menyelesaikan promosi produk mereka yang sangat menarik.

\section{UCAPAN TERIMAKASIH}

Tim kegiatan pengabdian pada masyarakat mengucapkan terima kasih kepada pihak-pihak yang telah berpartisipasi dalam kegiatan Pengabdian yang dilakukan. Terutama kepada Bapak Camat Medan Labuhan yang telah memberikan izin untuk dapat melaksanakan kegiatan ini dengan baik, dan terima kasih juga kepada peserta kegiatan ini yaitu ibu-ibu pengusaha makanan untuk dapat meluangkan waktu saling berbagi ilmu agar dapat meningkatan kemampuan dalam mendesain kemasan, edit dan mengupload makanan yang tampilannya sangat menarik dijual ke sosial media.

\section{REFERENSI}

Choi, S.W., et al. (20I5). Comparison of Risk and Protective Factors Associated with Smartphone Addiction and Internet Addiction. Journal of Bevahioral Addictions, 4(4), 308-3I 4.

Irenna, J.K dan Iwan. J.P. (20I8). Aktifitas Promosi Kuliner Di Kafe Titik Kumpul Surabaya Melalui Media Sosial. Jurnal Komunikasi Hasil Pemikiran dan Penelitian Vol. 4; No. 2.

Jean, M.R. (2018). Pengaruh Promosi Berbasis Teknologi Informasi Terhadap Pengusaha Muda Universitas Klabat. Cogito Smart Journal/VOL. 4/NO.I/June.

Williams, B.K. and Sawyer, S.C. 20II. Using Information Technology: A Practical Introduction to Computers \& Communications. (9th edition). New York: McGraw-Hill.
Yunita, Wardi, P. Susanto and N. L. Abdullah. (2017). Orientasi Kewirausahaan Pada Kinerja Usaha Kecil Menengah (UKM) Sumatera Barat: Analisis Peran Moderasi Dari Intensitas Persaingan, Turbelensi Pasar dan Teknologi. Jurnal Manajemen Teknologi, vol. 16, no. I. 